Research Article

\title{
Experimental Investigation on Carbonation Behavior in Lime-Stabilized Expansive Soil
}

\author{
Long Xu, ${ }^{1}$ Fusheng Zha $\mathbb{D}^{1}{ }^{1}$ Congmin Liu, ${ }^{1}$ Bo Kang, ${ }^{1}$ Jingjing Liu, ${ }^{1}$ and Chuang Yu ${ }^{2}$ \\ ${ }^{1}$ School of Resource and Environmental Engineering, Hefei University of Technology, Hefei 230009, China \\ ${ }^{2}$ College of Civil Engineering and Architecture, Wenzhou University, Wenzhou 325035, China \\ Correspondence should be addressed to Fusheng Zha; geozha@hfut.edu.cn
}

Received 19 September 2019; Accepted 13 January 2020; Published 24 February 2020

Academic Editor: Annan Zhou

Copyright $\left({ }_{0} 2020\right.$ Long Xu et al. This is an open access article distributed under the Creative Commons Attribution License, which permits unrestricted use, distribution, and reproduction in any medium, provided the original work is properly cited.

\begin{abstract}
The carbonation behavior of lime-stabilized expansive soil is important for assessing the stabilization efficiency from the perspective of durability. In this study, the accelerated carbonation tests, measurement of $\mathrm{pH}$ value distribution, and the free swell ratio tests were conducted to investigate the evolutions of carbonation depth, carbonation extent, and expansive potential of limestabilized expansive soil. XRD, MIP, and SEM techniques were adopted as supplements to reveal the carbonation mechanism. Results demonstrated that the carbonation depth of lime-stabilized expansive soil increased significantly as time elapsed; however, the rate of increase reduced when the carbonation time increased. Higher carbonation depth was obtained at higher temperature and $\mathrm{CO}_{2}$ concentration and lower relative humidity, which was described by an empirical model. Fully, partly, and noncarbonated zones were subsequently presented with an increase in the depth of the soil. The expansive potential of lime-stabilized expansive soil was partially recovered during carbonation. The obtained linear relationships between the free swell ratio and $\mathrm{pH}$ value were adopted to describe the evolution of expansive behavior with carbonation time and depth. In microstructural analysis, the conversion of portlandite into calcium carbonate was significant, which resulted in changes in microstructure and controlled the carbonation behavior.
\end{abstract}

\section{Introduction}

Expansive soil is found in tropical semiarid and moderate climatic regions and can trigger serious engineering hazards, such as foundation failure and slope instability, due to its swelling-shrinkage behavior and well-developed fissures during the water uptake/loss process [1-4]. Hence, the expansive potential of the soil is stabilized with the use of cement-based binding materials before constructions in these regions. For assessing the stabilization efficiency, the durability of the stabilized soil after being subjected to factors such as acid rain, sulfate attack, wetting-drying cycles, freezing-thawing cycles, and carbonation process is worthy of a detailed investigation [5-14].

Carbonation is one of the key durability properties that has attracted extensive attention in recent years. When the concrete or cement- and calcium-based materials are exposed to the atmosphere, $\mathrm{CO}_{2}$ will diffuse into the water or air phases in the pore space and reacts with portlandite $\left(\mathrm{Ca}(\mathrm{OH})_{2}\right)$ and calcium silicate hydrate $(\mathrm{C}-\mathrm{S}-\mathrm{H})$, to form calcium carbonate $\left(\mathrm{CaCO}_{3}\right)$ [15-17]. Carbonation starts from the surface and propagates to the center of the material; therefore, the deep understanding of carbonation front and propagation rate, namely, the carbonation depth and rate, is critical in assessing the extension in service life of stabilized soil or a concrete structure $[18,19]$. Based on literature review, Ta et al. [20, 21] summarized that the factors affecting carbonation depth and rate were chemical compositions and mix proportions in porous materials, along with temperature, relative humidity, concentration, and partial pressure of $\mathrm{CO}_{2}$ in the external environment $[19,22-24]$. Cui et al. [17] performed accelerated carbonation tests to study the effect of $\mathrm{CO}_{2}$ concentration on concrete carbonation, where four stages were identified based on the $\mathrm{CO}_{2}$ concentration ranging from $2 \%$ to $100 \%$. The increase in carbonation depth was significant when concrete was exposed to $\mathrm{CO}_{2}$ 
concentrations below 20\%; moreover, the effect reduced with any further increase in $\mathrm{CO}_{2}$ concentration. Similar carbonation tests by Hyvert et al. [23] confirmed the effect of $\mathrm{CO}_{2}$ pressure on the evolution of carbonation depth. Based on the distributed $\mathrm{pH}$ value along the height of the concrete mixture, Lu et al. [19] created fully and partly carbonated zones. Furthermore, although the carbonation depth increased gradually, the carbonation rate decreased with the carbonation time increase. The elevated temperature had minimal effect on the depth of the partly carbonated zones, but it instead resulted in greater depths for the fully carbonated zones. Additionally, the depths of both the fully and partly carbonated zones decreased with an increase in the relative humidity. For prediction of carbonation depth and rate of the porous materials under carbonation, simple empirical and enhanced physical models were proposed [18, 23, 25-27]. Investigations on carbonation mechanism showed that the formation of an insoluble salt of $\mathrm{CaCO}_{3}$ resulted in clogged pores with reduced pore size, which not only changed the carbonation front and propagation rate $[17,23,28]$, but also improved the strength and leaching characteristics of the stabilized material [6, 27, 28]. The significant effect of carbonation on the short-term and longterm strengths had been confirmed by Chen et al. [29], Nakarai and Yoshida [30], Du et al. [9], and Ho et al. [31], wherein the strength of cement-treated soil experienced an increase initially followed by a slight decrease over a long period. The microstructural analysis presented that $\mathrm{Ca}(\mathrm{OH})_{2}$ was primarily produced by cement hydration and consumed by carbonation and pozzolanic reactions, whereas $\mathrm{CaCO}_{3}$ was mostly provided by the carbonation of $\mathrm{Ca}(\mathrm{OH})_{2}$ and $\mathrm{C}-\mathrm{S}-\mathrm{H}$. The rapid increase in the strength initially was attributed to an increase in the amount of $\mathrm{CaCO}_{3}$ provided by $\mathrm{Ca}(\mathrm{OH})_{2}$. In contrast, under long-term conditions, increased $\mathrm{Ca}(\mathrm{OH})_{2}$ provided by C-S-H decreased the strength. Bin-Shafique et al. [32] and Sweeney et al. [33] reported that carbonation could decrease the buffer capacity and change the chemical compositions of the stabilized soil, which can accelerate the release of well-stabilized heavy metals. However, Lange et al. [34], Bertos et al. [35], and Du et al. [9] were of contrasting opinions. They comprehensively performed the acid-neutralizing capacity, toxicity characteristic leaching procedure, and microstructural analysis to confirm the positive effects of carbonation on the leachability of heavy metals in the stabilized soil.

Carbonation behavior investigations into concrete and cement-treated soil have progressed since the 1980s, which include describing the carbonation process, assessing the carbonation effect, and displaying the carbonated mechanism. However, due to the large amounts of $\mathrm{Ca}(\mathrm{OH})_{2}$ and $\mathrm{C}-\mathrm{S}-\mathrm{H}$ existing, forming, or participating during the stabilization process, the carbonation effect on lime-stabilized expansive soil is significant and worthy of investigation. Progressive carbonation, especially, may release the expansive potential of well-stabilized expansive soil, which may conversely influence the carbonation behavior due to changes in its microstructure. Until now, relevant researches on this issue have been rarely reported. Therefore, a series of tests, such as accelerated carbonation tests, $\mathrm{pH}$ value distribution measurements, free swell ratio tests, and microstructural analysis, are conducted in this study. Based on the results, the carbonation behavior in lime-stabilized expansive soil is described, the carbonation effect on the expansive potential is investigated, and the carbonation mechanism is revealed.

\section{Materials and Methods}

2.1. Materials and Specimen Preparation. The soils tested in this study were sampled from a construction site at a depth of 3-3.5 $\mathrm{m}$ in Hefei city, China. The physical properties of the soil were tested and are summarized in Table 1. The weakmedium expansibility for the tested soil can be identified. Based on X-ray fluorescence (XRF) analysis, the major chemical components were determined and listed in Table 2. Particle size distribution of the soil was tested using laser particle size analyzer and is presented in Figure 1. As can be seen, nonuniformity coefficient of 18.25 and curvature coefficient of 4.01 can be determined; silt content $(2-20 \mu \mathrm{m})$ of $59.40 \%$ and clay content $(<2 \mu \mathrm{m})$ of $40.62 \%$ were characterized for the tested soil. A maximum dry density of $1.63 \mathrm{~g} / \mathrm{cm}^{3}$ and an optimal water content of $24.05 \%$ were determined by the Proctor compaction test, in accordance with ASTM D698-12e2 (Figure 2). In this study, the lime purchased from a local building market in Hefei city, China, was used to stabilize the expansive soil. The chemical components of the lime were determined by performing XRF analysis, which were presented in Table 3.

When preparing the lime-stabilized expansive soil specimens, the mass ratio of lime to dry soil was set to $8 \%$ according to the excellent stabilization efficiency reported by Cheng et al. [36]. The oven-dried soil and lime were initially pulverized and sieved through 2.0 and $0.5 \mathrm{~mm}$ sieves, respectively. Based on the optimal water content (Figure 2), the target quantity of deionized water was sprayed on the lime-soil powder. After thorough mixing, the mixture was weighed and put in a ring mould. Static compaction was achieved with a piston at a rate of $0.1 \mathrm{kN} / \mathrm{min}$ to obtain target cylindrical specimens with $50 \mathrm{~mm}$ diameter, $100 \mathrm{~mm}$ height, and $1.55 \mathrm{~g} / \mathrm{cm}^{3}$ dry density, which was equivalent to $95 \%$ of the maximum dry density shown in Figure 2. The specimens were demoulded and wrapped with plastic bags and, then, cured under standard curing conditions (relative humidity of $95 \pm 4 \%$, temperature of $20 \pm 2^{\circ} \mathrm{C}$ ) for 28 days.

\subsection{Accelerated Carbonation Test. An accelerated carbon-} ation test was performed on the lime-stabilized specimen according to the Chinese standard GBT 50082-2009. A GangYuan TH-B environment-controlled carbonation chamber was used in the test as shown in Figure 3, where the temperature $(T)$, relative humidity $(R H)$, and carbon dioxide concentration $\left(C_{\mathrm{c}}\right)$ could be automatically controlled in the ranges of $15-30^{\circ} \mathrm{C}, 50 \%-90 \%$, and $0 \%-20 \%$ with corresponding accuracies of $\pm 2{ }^{\circ} \mathrm{C}, \pm 4 \%$, and $\pm 3 \%$, respectively.

The lime-stabilized specimens were extracted from the curing room after 28 days. One side of the specimen was chosen as the carbonated surface and was exposed to the 
TABLE 1: Basic physicochemical properties of the tested expansive soil.

\begin{tabular}{lc}
\hline Index & Value \\
\hline Water content, $w(\%)$ & 21.5 \\
Natural density, $\rho\left(\mathrm{g} / \mathrm{cm}^{3}\right)$ & 1.95 \\
Specific gravity, $G_{\mathrm{s}}$ & 2.73 \\
Plastic limit, $w_{p}(\%)$ & 22.4 \\
Liquid limit, $w_{L}(\%)$ & 48.9 \\
Plastic index, $I_{\mathrm{P}}$ & 26.5 \\
Free selling ratio, $\delta_{e f}(\%)$ & 55 \\
\hline
\end{tabular}

external environment, while the remaining five surfaces were coated with epoxy resin, to ensure unidirectional carbonation. Next, the prepared specimen was placed in the carbonation chamber with $T$ as $15^{\circ} \mathrm{C}, 20^{\circ} \mathrm{C}, 25^{\circ} \mathrm{C}$, and $30^{\circ} \mathrm{C}$, $R H$ as $60 \%, 70 \%, 80 \%$, and $90 \%$, and $C_{\mathrm{c}}$ as $5 \%, 10 \%, 15 \%$, and $20 \%$, while being controlled subsequently. In each test exploring the influence induced by changes in one of the $T$, $R H$, and $C_{c}$, the other two parameters should be kept constant at the standard carbonation condition ( $T$ as $20 \pm 2^{\circ} \mathrm{C}, R H$ as $70 \pm 4 \%$, and $C_{\mathrm{c}}$ as $20 \pm 3 \%$ ). During carbonation, the specimens were extracted from the carbonation chamber at regular intervals and split using a scroll saw. The freshly split surface was cleaned and sprayed with phenolphthalein, known as a typical $\mathrm{pH}$ indicator. The indicator used was a phenolphthalein solution $1 \%$ in ethanol with $1 \mathrm{~g}$ phenolphthalein and $90 \mathrm{ml}$ of $95 \%(\mathrm{v} / \mathrm{v})$ ethanol diluted in $100 \mathrm{ml}$ of water $[37,38]$. The phenolphthaleinalcohol solution was a colorless acid-base indicator, which turned purple when the $\mathrm{pH}$ value of the pore solution went above 9; hence, the carbonation front was easy to identify. Typical results obtained from this study are shown in Figure 4 . The carbonation depth can be easily determined using the average value at five locations.

2.3. $p H$ Value Distribution Measurement. In the accelerated carbonation test, the specimen was distinctly divided into fully carbonated and noncarbonated zones based on the critical $\mathrm{pH}$ value of 9 determined using the phenolphthalein indicator. However, the specimen undergoing carbonation actually had a fully carbonated zone, noncarbonated zone, and transitional region (termed as partly carbonated zone), which should be detected based on the measured $\mathrm{pH}$ value distribution along the height of the specimen $[19,39]$. For investigating the carbonation extent in the lime-stabilized expansive soil, two additional specimens at different carbonation times (around $2 \mathrm{~d}$ and $5 \mathrm{~d}$ ) were prepared under the standard carbonation condition $\left(T\right.$ as $20 \pm 2^{\circ} \mathrm{C}, R H$ as $70 \pm 4 \%$, and $C_{\mathrm{c}}$ as $20 \pm 3 \%$ ). First, the corresponding carbonation depths measured using the phenolphthalein indicator were 25 and $44 \mathrm{~mm}$, respectively. Furthermore, each of them was cut into five circular disks at every $20 \mathrm{~mm}$ height. Next, the cut samples were pulverized and sieved through a $2 \mathrm{~mm}$ mesh. $10 \mathrm{~g}$ of the sample was thoroughly mixed with $10 \mathrm{ml}$ of deionized water followed by $1 \mathrm{~h}$ deposition. Finally, the supernatant was filtered and the corresponding $\mathrm{pH}$ value was measured using the $\mathrm{pH}$ meter to obtain the $\mathrm{pH}$ distribution of the specimen. Additionally, two referenced lime-stabilized expansive specimens were prepared and cured under standard curing conditions for 28 days. One of them was directly adopted for $\mathrm{pH}$ value distribution measurement, and the other was fully carbonated for one month before $\mathrm{pH}$ value measurement. On this basis, the reference $\mathrm{pH}$ values for noncarbonated and fully carbonated specimens can be obtained.

2.4. Free Swell Ratio Test. For investigating the expansive potential of lime-stabilized specimens undergoing carbonation, two additional stabilized specimens were prepared followed by experiencing standard carbonations. At carbonation times around $2 \mathrm{~d}$ and $5 \mathrm{~d}$, the specimens were subsequently extracted and the corresponding carbonation depths were measured using the phenolphthalein indicator, which were 25 and $44 \mathrm{~mm}$, respectively. Then, each of them was cut into five circular disks at every $20 \mathrm{~mm}$ height and then oven-dried at $105^{\circ} \mathrm{C}$ for $24 \mathrm{~h}$. The samples were pulverized and sieved through a $0.5 \mathrm{~mm}$ mesh followed by the free swell ratio tests performed according to the Chinese standard JTG E40-2007.

2.5. Microstructural Analysis. Specimens were exclusively prepared and cured under standard curing conditions, followed by carbonation under standard conditions. After a carbonation time around $8 \mathrm{~d}$, the specimens were extracted and the corresponding carbonation depth measured using the phenolphthalein indicator was found to be $55 \mathrm{~mm}$. Then, the $\mathrm{pH}$ value distribution of the specimen was measured using a $\mathrm{pH}$ meter, which was adopted to divide the carbonated zone into a fully carbonated zone $(\mathrm{pH}$ value $<9)$, partly carbonated zone $(9 \leq \mathrm{pH}$ value $<11)$, and noncarbonated zone $(\mathrm{pH}$ value $\geq 11)$ according to previous researches. Finally, a microstructural analysis was performed in the different zones of the specimen. As shown in Figure 5, samples in fully carbonated and noncarbonated zones were extracted, pulverized, and sieved through a $0.5 \mathrm{~mm}$ mesh, to analyze the chemical components using $\mathrm{X}$-ray diffraction (XRD). Samples with dimensions of $5 \mathrm{~mm} \times 5 \mathrm{~mm} \times 5 \mathrm{~mm}$ in fully carbonated and noncarbonated zones were adopted to analyze the mineralogical compositions and micromorphology using a scanning electron microscopy (SEM). Samples with dimensions of approximately $3 \mathrm{~mm} \times 3 \mathrm{~mm} \times 3 \mathrm{~mm}$ and masses between 1.5 and $2.0 \mathrm{~g}$ in fully carbonated, partly carbonated, and noncarbonated zones were adopted to analyze the pore size distribution using mercury intrusion porosimetry (MIP). The referred testing procedures related to XRD, MIP, and SEM are described in detail by Du et al. [9] and Shah et al. [40].

\section{Results and Discussion}

3.1. Evolution of Carbonation Depth of Lime-Stabilized Expansive Soil. Evolutions of carbonation depth with time of the lime-stabilized expansive soil, with consideration to changes in temperature, relative humidity, and carbon dioxide concentration, are presented in Figure 6(a)-6(c), respectively. 
TABLE 2: Major chemical components of the tested soil.

\begin{tabular}{lccccccccc}
\hline Chemical component & $\mathrm{SiO}_{2}$ & $\mathrm{Al}_{2} \mathrm{O}_{3}$ & $\mathrm{Fe}_{2} \mathrm{O}_{3}$ & $\mathrm{~K}_{2} \mathrm{O}$ & $\mathrm{MgO}$ & $\mathrm{CaO}$ & $\mathrm{Na}_{2} \mathrm{O}$ & $\mathrm{MnO}$ & $\mathrm{Others}$ \\
\hline Content (\%) & 68.52 & 14.87 & 7.81 & 2.33 & 2.07 & 1.22 & 1.10 & 0.18 & 1.81 \\
\hline
\end{tabular}

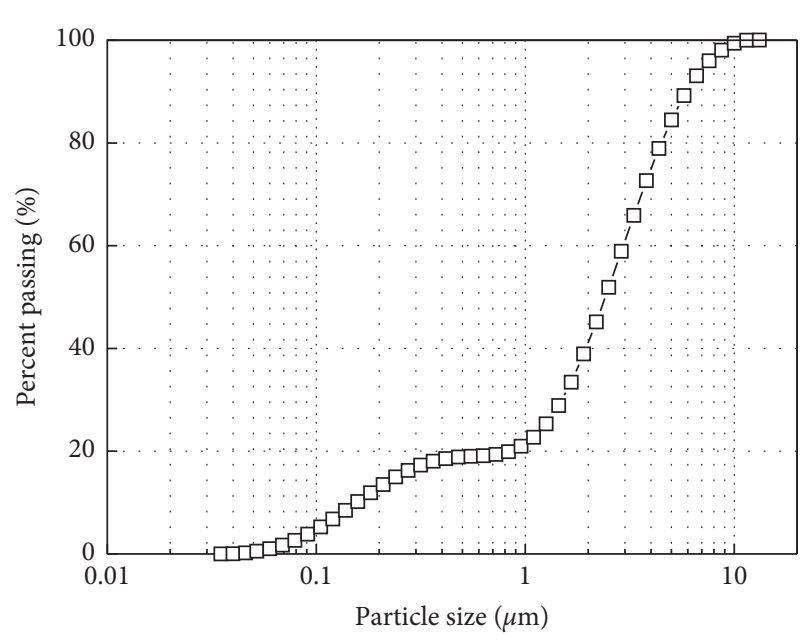

FIgURE 1: Particle size distribution of the tested soil.

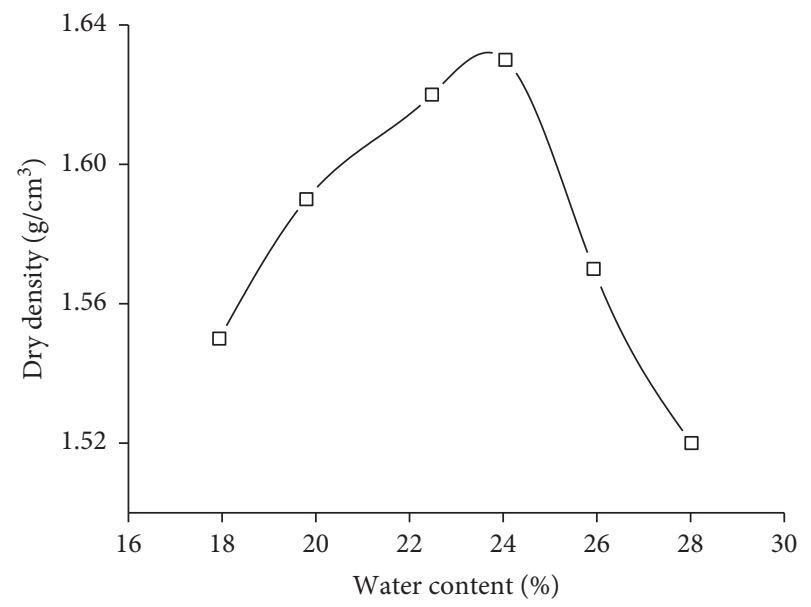

Figure 2: Compaction curve of the tested soil.

As shown in Figure 6, the carbonation depth of the limestabilized expansive soil increases with time elapsing. The increasing rate is significant in the initial stage followed by a relatively stable trend over a long period of time. Similar results were previously observed through tests performed on normal concrete and fly ash concrete [19]. This is because of the fact that, owing to the $\mathrm{CO}_{2}$ concentration gradient between the external and internal environment, $\mathrm{CO}_{2}$ diffuses into the specimen and proceeds with time, during which carbonation occurs in the specimens involved in the interaction between the $\mathrm{CO}_{2}$ and $\mathrm{Ca}(\mathrm{OH})_{2}$, or $\mathrm{C}-\mathrm{S}-\mathrm{H}$. The resulting products $\mathrm{CaCO}_{3}$ will clog the soil pores and conversely impedes the $\mathrm{CO}_{2}$ diffusion. Thus, the carbonation rate approaches a stable level with time [19, 28, 41].

Curves in Figure 6 also present that the higher temperature or $\mathrm{CO}_{2}$ concentration in the environment results in a higher carbonation depth at a given carbonation time, while the higher relative humidity in the environment results in a lower carbonation depth at a given carbonation time. This is because a higher temperature can promote the $\mathrm{CO}_{2}$ diffusion rate in a porous medium and decrease the degree of saturation of the specimen, which will conversely increase the diffusing capacity of $\mathrm{CO}_{2}$. Similarly, the higher $\mathrm{CO}_{2}$ concentration can directly improve the diffusing capacity of $\mathrm{CO}_{2}$ due to the enhanced concentration gradient in the specimen, while the higher relative humidity increases the liquid saturation in the pore space and reduces $\mathrm{CO}_{2}$ diffusion accordingly $[17,19,23]$.

For the carbonation behavior in concrete or cement- and calcium-based materials, prediction of carbonation depth using simple empirical or enhanced models with implied physical mechanism was proposed in the past decades $[18,23,26,27]$. For simplicity, the evolution of carbonation depth was normally regarded as a function of the square root of time, in previous researches, as shown in the following equation:

$$
x_{c}=k_{c} \cdot \sqrt{t}
$$

where $x_{\mathrm{c}}$ is the carbonation depth $(\mathrm{mm}) ; t$ is the carbonation time $(\mathrm{d}) ; k_{\mathrm{c}}$ is the carbonation coefficient $\left(\mathrm{mm} / \mathrm{d}^{0.5}\right)$, which depends on the inherent properties of the material, as well as the external environment such as temperature, relative humidity, and carbon dioxide concentration.

Based on Figure 6, the relationships between carbonation depth and square root of carbonation time in terms of the effect of temperature, relative humidity, and carbon dioxide concentration are shown in Figures $7(a)-7(\mathrm{c})$, respectively. Linear relationships between the carbonation depth and square root of carbonation time can be observed for conducting tests under different conditions. The slope of a line indicating the carbonation coefficients $\left(k_{\mathrm{c}}\right)$, which are dependent on the test conditions, is summarized and listed in Table 4. Based on this, the relationships between carbonation coefficient and temperature, relative humidity, and carbon dioxide concentration are plotted in Figures 8(a)$8(\mathrm{c})$, respectively.

As shown in Figure 8, with an increase in temperature and carbon dioxide concentration, and a decrease in relative humidity, the carbonation coefficient is linearly increased. Based on the superposition principle, the carbonation coefficient can be expressed as

$$
k_{c}=M+m \cdot T+n \cdot R H+l \cdot C_{c} .
$$

where $T$ is the temperature $\left({ }^{\circ} \mathrm{C}\right) ; R H$ is the relative humidity (\%); $C_{\mathrm{c}}$ is the carbon dioxide concentration (\%); $M$ is the intercept and $m, n, l$ are the slopes of the linear relationship between the carbonation coefficient and the temperature, relative humidity, and carbon dioxide 
TABLE 3: Major chemical components of the used lime.

\begin{tabular}{lcccccccc}
\hline Chemical component & $\mathrm{CaO}$ & $\mathrm{MgO}$ & $\mathrm{SiO}_{2}$ & $\mathrm{Al}_{2} \mathrm{O}_{3}$ & $\mathrm{Fe}_{2} \mathrm{O}_{3}$ & $\mathrm{~K}_{2} \mathrm{O}$ & LOI & Total \\
\hline Content (\%) & 73.12 & 1.89 & 0.62 & 0.28 & 0.23 & 0.05 & 22.48 & 98.67 \\
\hline
\end{tabular}

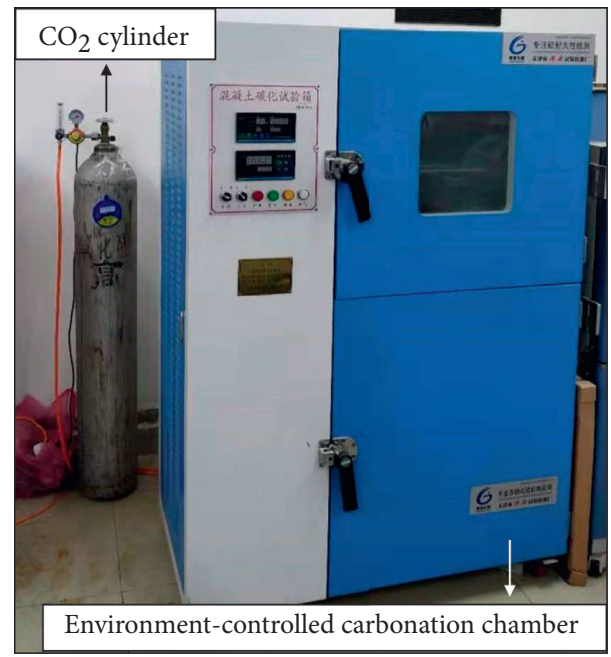

FIgURE 3: Environment-controlled carbonation chamber adopted in this study.

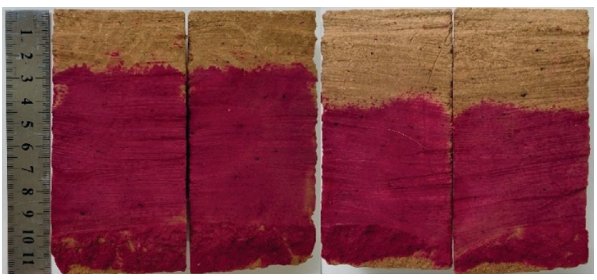

FIGURE 4: Determination of the carbonation depth of the tested soil.

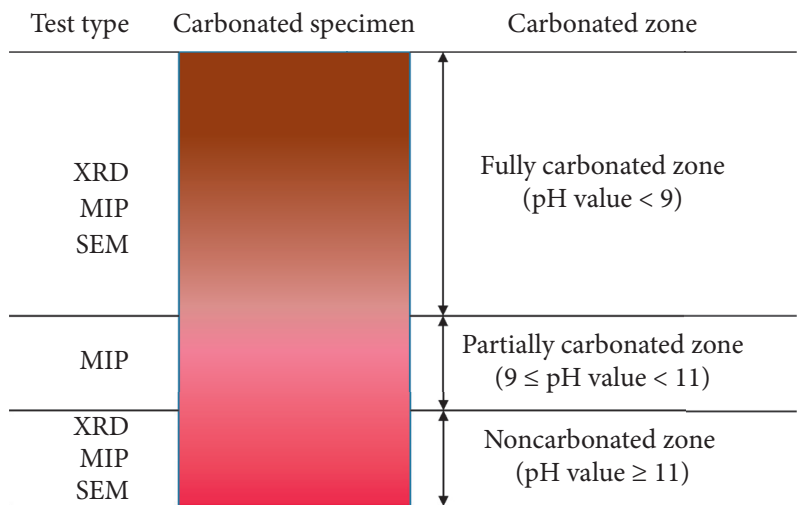

Figure 5: Sampling locations for microstructural analysis of the specimen.

concentration, respectively. Based on the results of Figure 8, $m=0.3358, n=-0.5198$, and $l=0.582$ can be obtained when $M$ is equal to $35.91,36.15$, and 38.07 , respectively. Due to the minimal difference, an average value of $M$ equal to 36.71 is adopted in the present study for simplicity. Finally, evolution of carbonation coefficient with temperature, relative humidity, and carbon dioxide concentration can be obtained as shown in the following equation:

$$
k_{c}=36.71+0.3358 \cdot T-0.5198 \cdot R H+0.582 \cdot C_{c} .
$$

Furthermore, by substituting Equation (3) with Equation (1), evolution of carbonation depth with time can be predicted using the following equation:

$$
x_{c}=\left[36.71+0.3358 \cdot T-0.5198 \cdot R H+0.582 \cdot C_{c}\right] \cdot \sqrt{t} .
$$

3.2. Evolution of Carbonation Extent of Lime-Stabilized Expansive Soil. The carbonation extent of lime-stabilized expansive soil can be reflected by the $\mathrm{pH}$ value distribution measured using a $\mathrm{pH}$ meter. The results for specimens with carbonation depths of 25 and $44 \mathrm{~mm}$ are presented in Figure 9. The referenced $\mathrm{pH}$ value distribution for fully carbonated and noncarbonated specimens is also shown in the figure.

Curves in Figure 9 show nonuniform distributions of $\mathrm{pH}$ value in the carbonated specimens. At the top surface, $\mathrm{pH}$ values are significantly lower than 9 , even approaching 6 , indicating the fully carbonated zones of the specimen. With an increase in depth from the top surface, $\mathrm{pH}$ value increases and becomes stable with values almost equal to 11.4, indicating the noncarbonated zones of the specimen. Additionally, it is clear that specimens experiencing a longer carbonation time have lower $\mathrm{pH}$ values at a given depth. These evolutions of $\mathrm{pH}$ values were attributed to the conversion of $\mathrm{Ca}(\mathrm{OH})_{2}$ and $\mathrm{C}-\mathrm{S}-\mathrm{H}$ to $\mathrm{CaCO}_{3}$, which imply that 


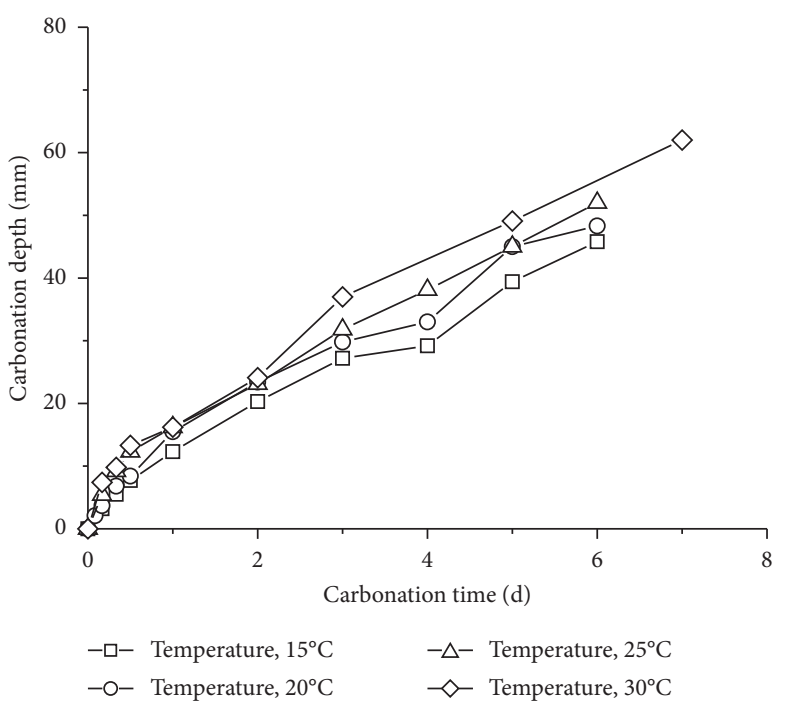

(a)

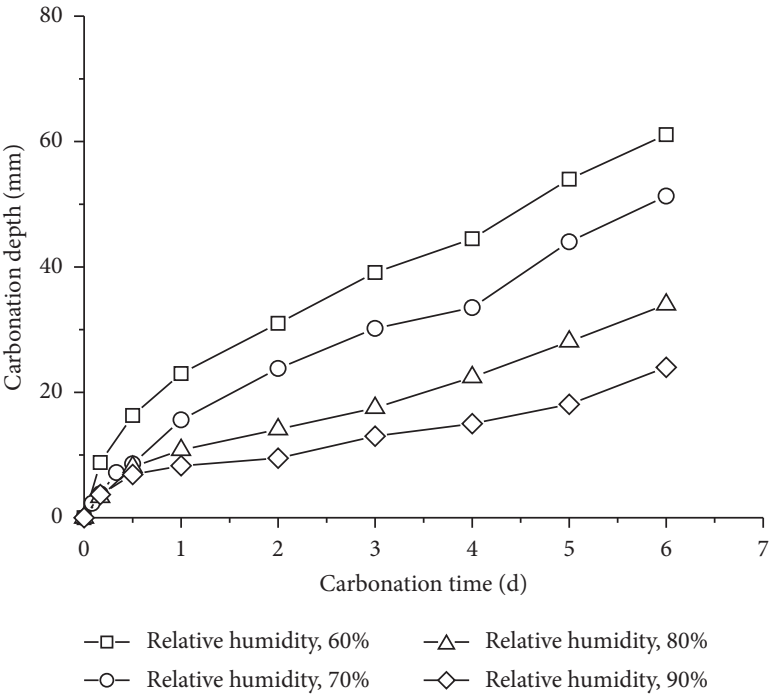

(b)

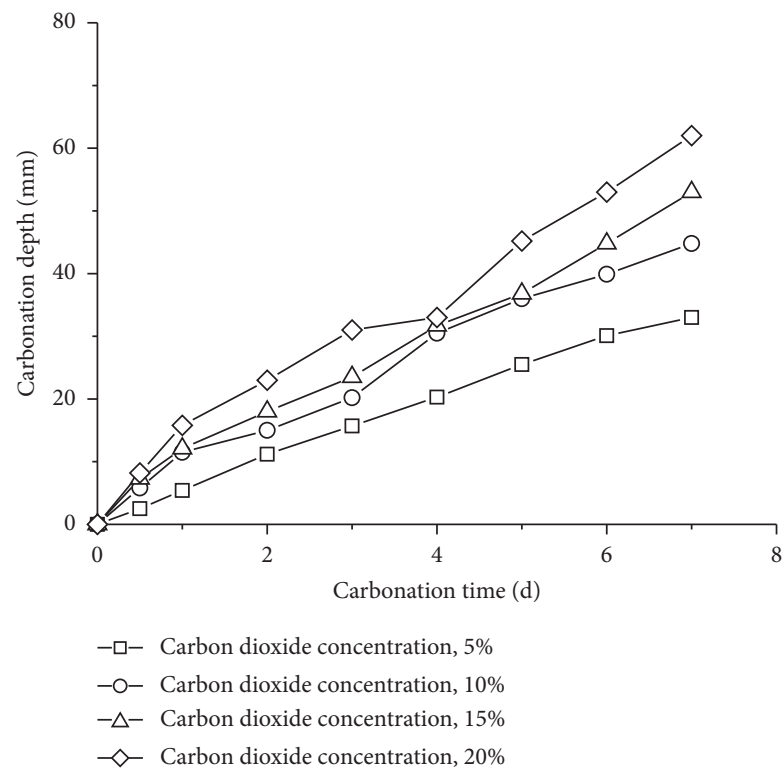

(c)

Figure 6: Evolution of carbonation depth with time of the lime-stabilized expansive soil, effect of (a) temperature, (b) relative humidity, and (c) carbon dioxide concentration.

the carbonation extent reduces with an increase in carbonation depth and a decrease in carbonation time [13-17].

Based on carbonation depths of 0,25 , and $44 \mathrm{~mm}$ measured using the phenolphthalein indicator and temperature of $20^{\circ} \mathrm{C}$, relative humidity of $70 \%$, and carbon dioxide concentration of $20 \%$, the accurate carbonation time for these tests is determined as $0 \mathrm{~d}, 1.79 \mathrm{~d}$, and $5.55 \mathrm{~d}$ using Equation (4). Therefore, the evolution of carbonation extent (reflected by $\mathrm{pH}$ value) with time can be quantitatively plotted as shown in Figure 10.

As shown in Figure 10, carbonation on lime-stabilized expansive soil does not show uniform propagation. First, the top zone of the specimen is carbonated and it reaches the fully carbonated zone quite rapidly in a short time.
However, with an increase in depth, from the top of the specimen, the carbonation extent becomes limited, especially at the bottom zone; thus, insignificant carbonation is presented. The continuously formed $\mathrm{CaCO}_{3}$ resulting from the carbonation blocks the soil pores, leading to a denser structure of the specimen. Subsequently, $\mathrm{CO}_{2}$ diffusion can hardly proceed in a further depth of the specimen. As a result, the carbonation extent is limited during the long-term exposure to $\mathrm{CO}_{2}$ $[17,19,28,41]$. Furthermore, curves shown in Figure 10 indicate that the carbonation extent is a function of depth and time. On this basis, the evolution of the carbonation extent (reflected by $\mathrm{pH}$ value) can be quantitatively illustrated, as in Figure 11. 


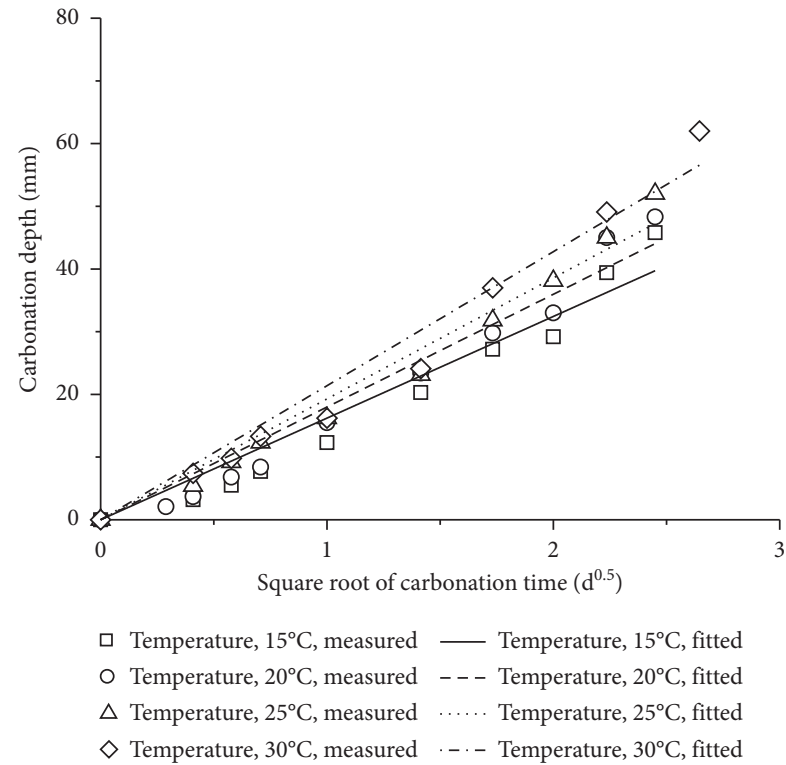

(a)

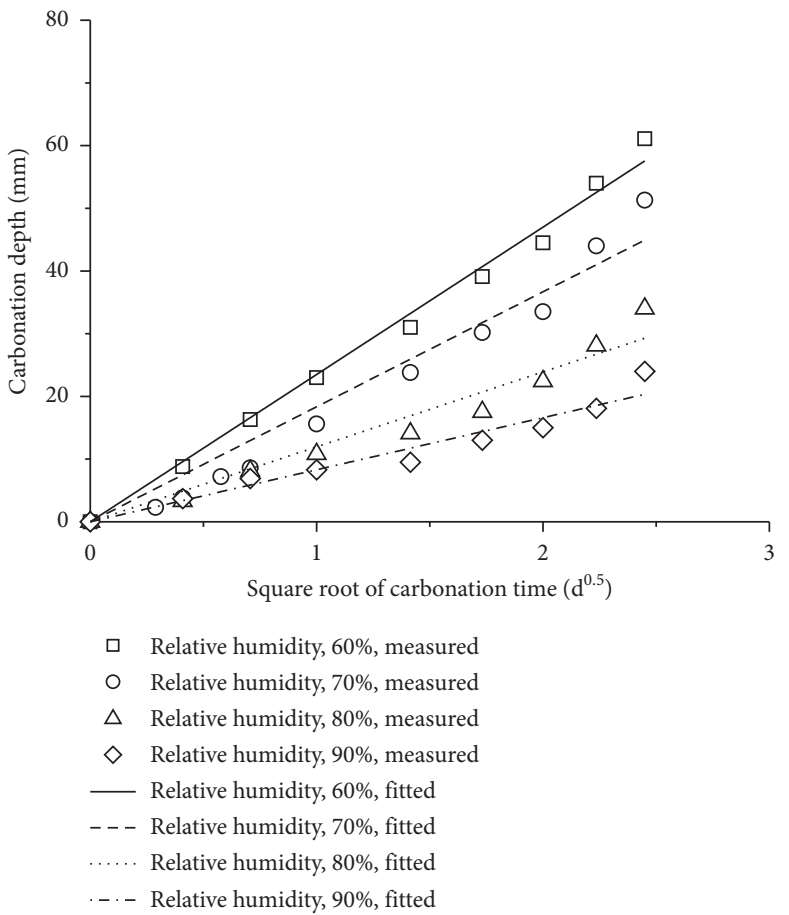

(b)

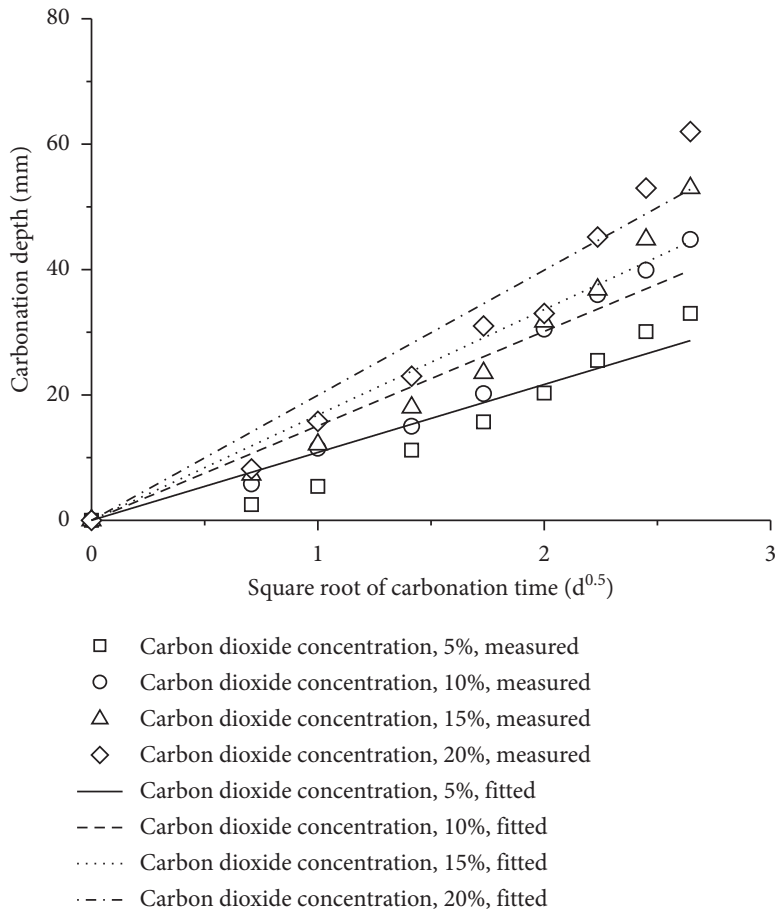

(c)

FIGURE 7: Relationships between carbonation depth and square root of carbonation time, effect of (a) temperature, (b) relative humidity, and (c) carbon dioxide concentration.

3.3. Evolution of Expansive Potential of Lime-Stabilized Expansive Soil. The evolution of expansive potential for specimens with carbonation depths of 25 and $44 \mathrm{~mm}$ is shown in Figure 12.
As shown in Figure 12, the expansive potential of the specimen recovers after carbonation. A high free swell ratio of $30 \%$ can be observed at the top zone of the specimen. With an increase in depth from the top of the 
TABLE 4: Carbonation coefficients obtained during accelerated carbonation test.

\begin{tabular}{lcc}
\hline Test condition & $k_{\mathrm{c}}$ & $R^{2}$ \\
\hline Temperature, $15^{\circ} \mathrm{C}$ & 16.22 & 0.9772 \\
Temperature, $20^{\circ} \mathrm{C}$ & 17.98 & 0.9824 \\
Temperature, $25^{\circ} \mathrm{C}$ & 19.29 & 0.9909 \\
Temperature, $30^{\circ} \mathrm{C}$ & 21.38 & 0.9863 \\
\hline Relative humidity, 60\% & 23.50 & 0.9972 \\
Relative humidity, 70\% & 18.34 & 0.9815 \\
Relative humidity, 80\% & 11.96 & 0.9827 \\
Relative humidity, 90\% & 8.30 & 0.9820 \\
\hline Carbon dioxide concentration, 5\% & 10.84 & 0.9618 \\
Carbon dioxide concentration, 10\% & 15.07 & 0.9746 \\
Carbon dioxide concentration, 15\% & 16.81 & 0.9730 \\
Carbon dioxide concentration, 20\% & 19.96 & 0.9765 \\
\hline
\end{tabular}

specimen, the recovered expansive potential becomes limited. For a given depth, the specimen with a carbonation depth of $44 \mathrm{~mm}$ owns a higher recovery of the expansive potential than that with a carbonation depth of $25 \mathrm{~mm}$. From the results shown in Figure 12, it can be concluded that an excellent stabilization efficiency is guaranteed only for depths above $70 \mathrm{~mm}$ for specimens with a carbonation depth of $25 \mathrm{~mm}$. Possible reasons could be summarized that, in initial stabilization, the complicated physicochemical process, for example, pozzolanic reactions, constrained the expansive potential and enhanced the density of the lime-stabilized expansive soil. However, in carbonation, the conversion of $\mathrm{Ca}(\mathrm{OH})_{2}$ and C-S-H into $\mathrm{CaCO}_{3}$ releases the expansive potential and reduces the density of the soil. Additionally, the formation and growth of $\mathrm{CaCO}_{3}$ in carbonation would have an expansive ratio of approximately $11.7 \%$, which can increase the solid volume in the specimen as well $[17,42]$. Based on Figures 9 and 12, it can be seen that a higher carbonation extent (a lower $\mathrm{pH}$ value) indicated a higher expansive potential of the specimen. Therefore, a relationship between the free swell ratio and the previously determined $\mathrm{pH}$ value can be plotted as shown in Figure 13.

As shown in Figure 13, linear relationships exist between the free swell ratio and $\mathrm{pH}$ value for specimens with different carbonation depths (time), confirming a strong dependency of expansive potential on carbonation extent. Theoretically, a unique fitted line can be obtained for carbonated specimens with different carbonation depths, a scenario not shown in Figure 13. This discrepancy may be attributed to the different microstructures in specimen preparation and the continuous microstructural changes caused by carbonation. The detailed reasons to this discrepancy could be explored in further researches. However, for qualitative and simple investigation of the swelling potential of the specimens during carbonation process, a fitted line of the average values is obtained through the collected data, which is shown in Figure 13 and expressed in the following equation:

$$
\delta_{e f}=53.61-3.95 \times \mathrm{pH}
$$

Here, $\delta_{e f}$ is the free swell ratio of the carbonated specimen (\%); $\mathrm{pH}$ is the $\mathrm{pH}$ value measured using a $\mathrm{pH}$ meter.

Based on Equation (5) and the results shown in Figure 10, evolution of free swell ratio with carbonation time and depth for lime-stabilized expansive soil is presented in Figure 14.

As shown in Figure 14, the recovery of expansive potential increases with an increase in the carbonation time. This increasing trend is significant at the top of the specimen. With an increase in depth from the top surface, the increase in expansive potential turns limited. This phenomenon indicates that carbonation has a deteriorative effect on the stabilization efficiency of the lime-stabilized expansive soil. However, this deterioration effect is not uniformly distributed in the specimen. The stabilization efficiency can be guaranteed at a depth far away from the carbonated surface, which may be attributed to the reduced carbonation effect due to pore clogging and shrinkage during carbonation.

\subsection{Microstructural Analysis of Carbonation Mechanism.} Carbonation behavior is normally accompanied by mineralogical and microstructural changes in the specimen, which conversely influence the carbonation behavior. To reveal the carbonation mechanism, XRD, MIP, and SEM were performed in different carbonated zones. The results are presented in Figures 15-17.

A qualitative XRD analysis is shown in Figure 15. This shows significant mineralogical changes in the specimen after carbonation. Compared to the results of noncarbonated zones, $\mathrm{Ca}(\mathrm{OH})_{2}$ disappears and $\mathrm{CaCO}_{3}$ emerges in the fully carbonated zone with almost constant amount of C-S-H. Castellote et al. [43], Ho et al. [31], and Shah et al. [40] reported that the formation of $\mathrm{CaCO}_{3}$ was mostly due to the carbonation of the hydration products including $\mathrm{Ca}(\mathrm{OH})_{2}$ and $\mathrm{C}-\mathrm{S}-\mathrm{H}$ gel, which resulted in different volumetric characteristics during carbonation. It is evident that the conversion of $\mathrm{Ca}(\mathrm{OH})_{2}$ into $\mathrm{CaCO}_{3}$ is the main mechanism that controls the carbonation behavior in lime-stabilized expansive soils. This mechanism implies that the consumption of $\mathrm{Ca}(\mathrm{OH})_{2}$ destroys the alkaline condition and reduces the $\mathrm{pH}$ value, which is similar to the results of Figure 9. Additionally, with the ion exchange and aggregate effect, the pozzolanic reaction is prevented due to the reduced $\mathrm{Ca}^{2+}$ and $\mathrm{pH}$ value in the reactive system, thus releasing the expansive potential of the specimen as shown in Figure 12.

By performing the MIP tests, the measured pore size distributions in noncarbonated, partly carbonated, and fully carbonated zones are shown in Figure 16, confirming a significantly reduced pore volume after carbonation. Although the amount of medium-sized pores, of around $0.5 \mu \mathrm{m}$, increases slightly after carbonation, the amount of 


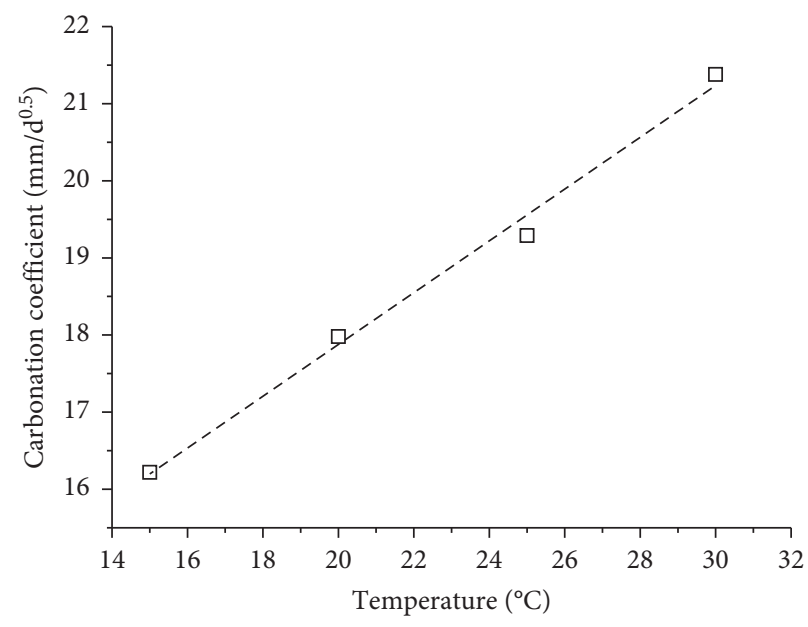

(a)

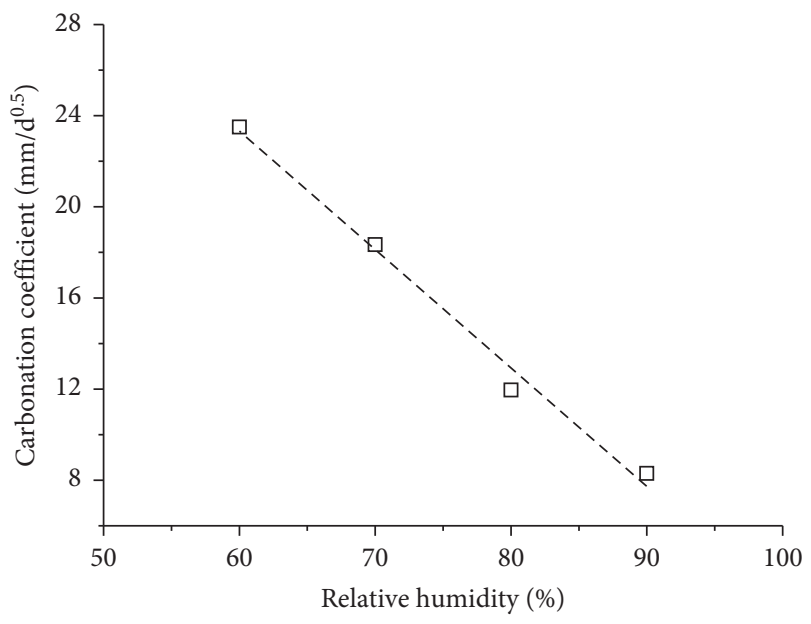

(b)

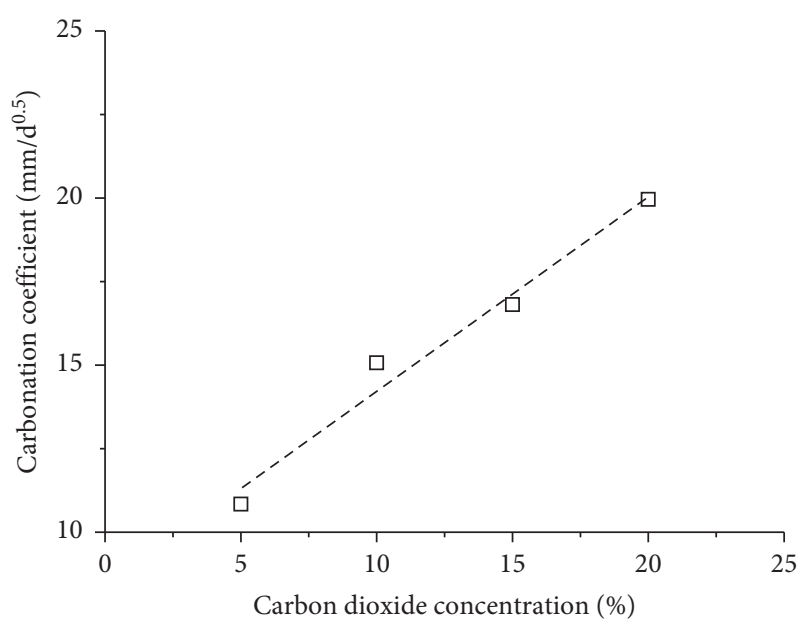

(c)

FIGURE 8: Relationships between carbonation coefficient and (a) temperature, (b) relative humidity, (c) carbon dioxide concentration.

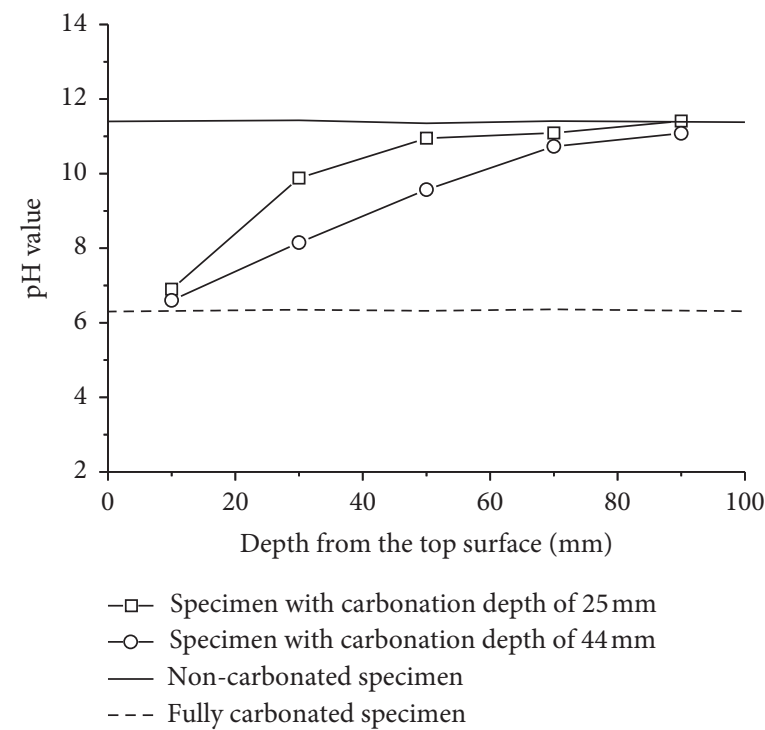

Figure 9: Distribution of $\mathrm{pH}$ value in the carbonated specimen. 


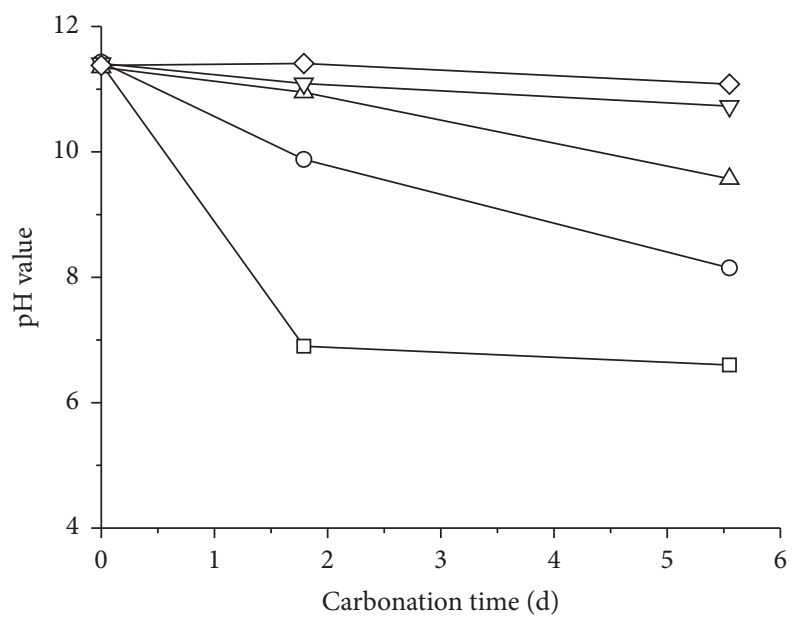

$-\square$ Depth from the top surface, $10 \mathrm{~mm}$
- - Depth from the top surface, $30 \mathrm{~mm}$
$\triangle$ Depth from the top surface, $50 \mathrm{~mm}$
$-\checkmark$ Depth from the top surface, $70 \mathrm{~mm}$
$\checkmark-$ Depth from the top surface, $90 \mathrm{~mm}$

FIGURE 10: Evolution of carbonation extent with time of lime-stabilized expansive soil.

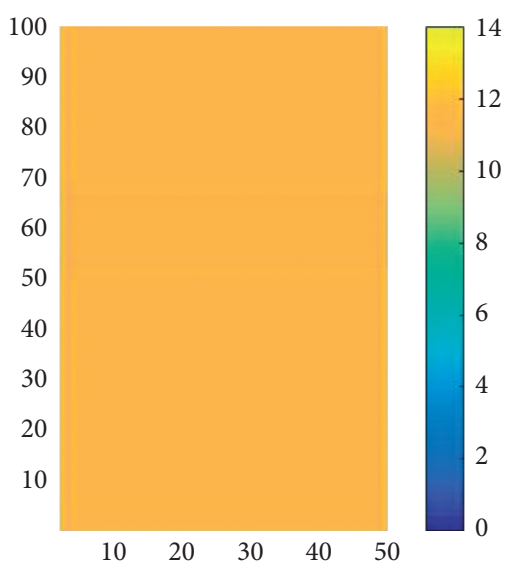

(a)

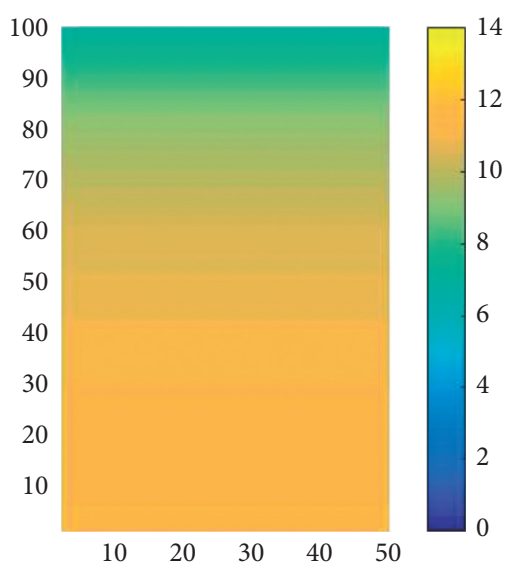

(d)

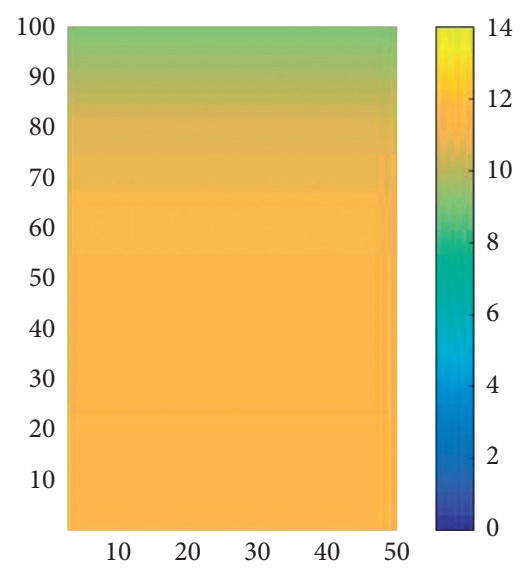

(b)

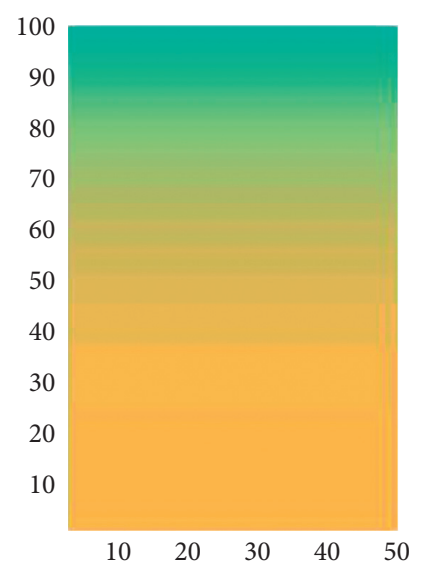

(e)

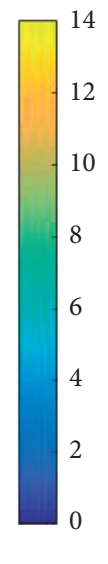

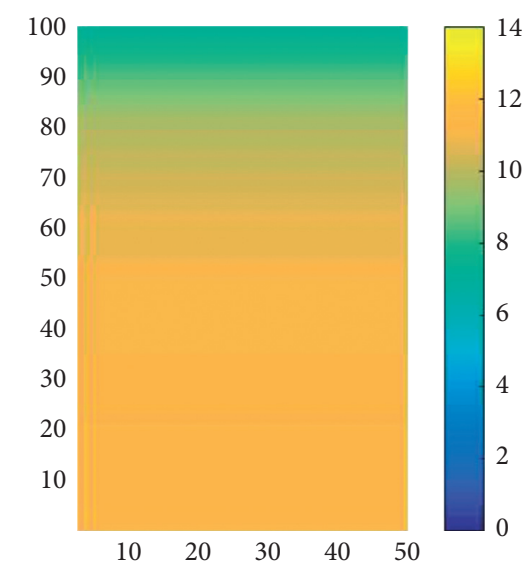

(c)

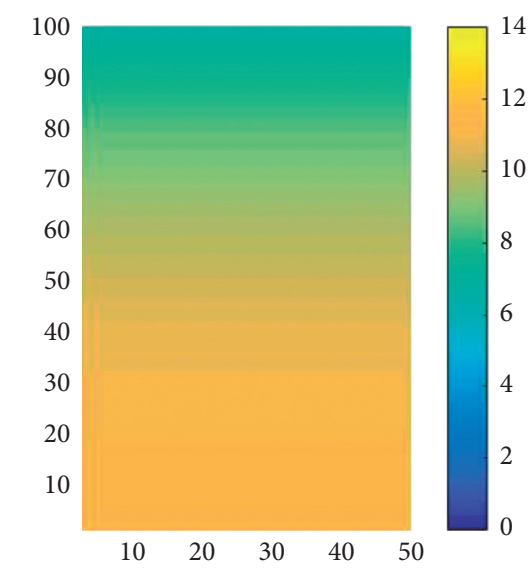

(f)

FIgURe 11: Evolution of carbonation extent of lime-stabilized expansive soil (using MATLAB). (a) Carbonation time-0 d. (b) Carbonation time-1 d. (c) Carbonation time-2 d. (d) Carbonation time-3 d. (e) Carbonation time-4 d. (f) Carbonation time-5 d. 


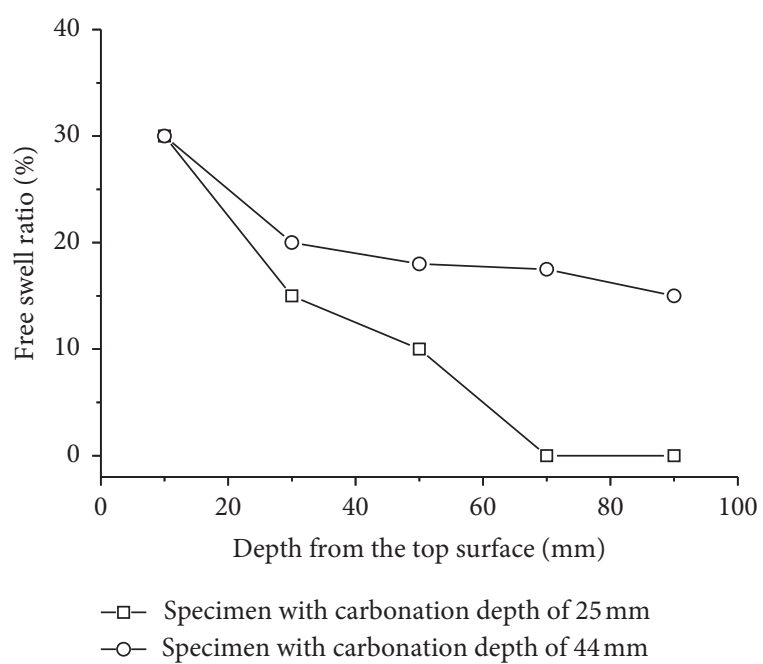

FIGURE 12: Distribution of free swell ratio of lime-stabilized expansive soil after carbonation.

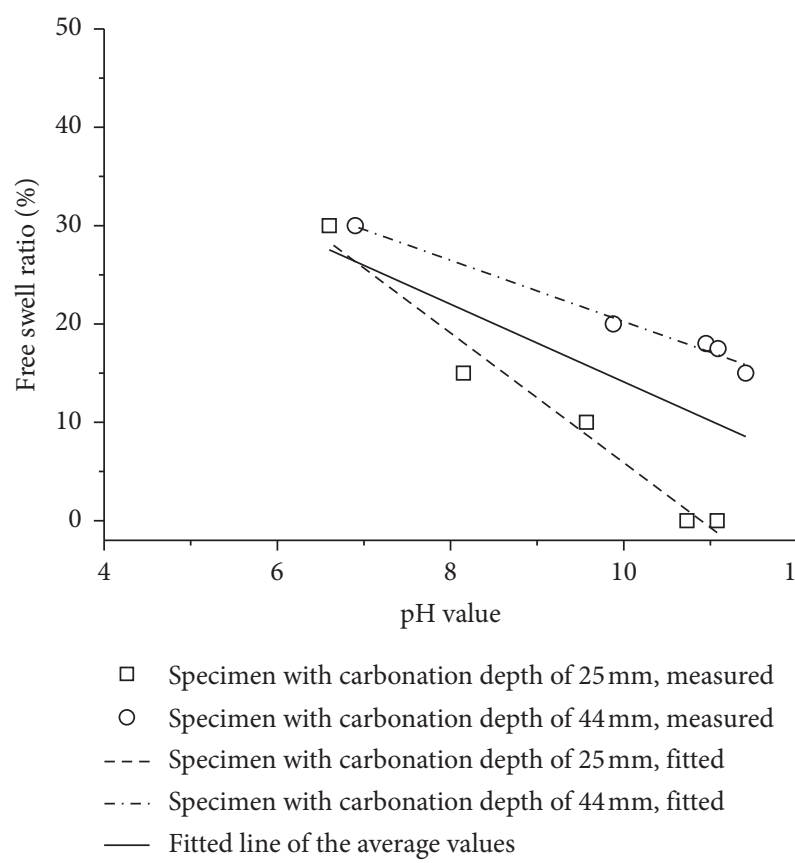

FIgURE 13: Relationship between the free swell ratio and $\mathrm{pH}$ value of lime-stabilized expansive soil.

small-sized and large-sized pores notably reduces during carbonation. This phenomenon is consistent with the conclusions reached by Cui et al. [17], Du et al. [9], and Ho et al. [31], which observed reduced pore volume for specimens experiencing carbonation, further leading to improved strength and leaching properties of the specimen. Morandeau et al. [42] and Cui et al. [17] indicated that the formation and growth of $\mathrm{CaCO}_{3}$ during carbonation clogged the pores and reduced their sizes. As a result, the evolution of the carbonation depth and carbonation extent could be

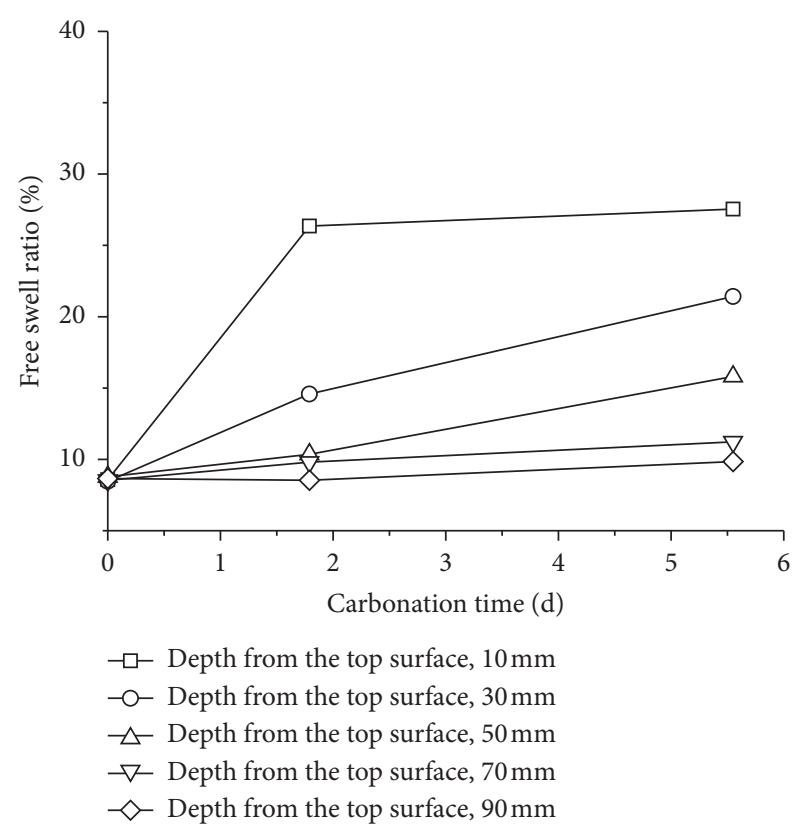

Figure 14: Evolution of free swell ratio with carbonation time and depth for lime-stabilized expansive soil.

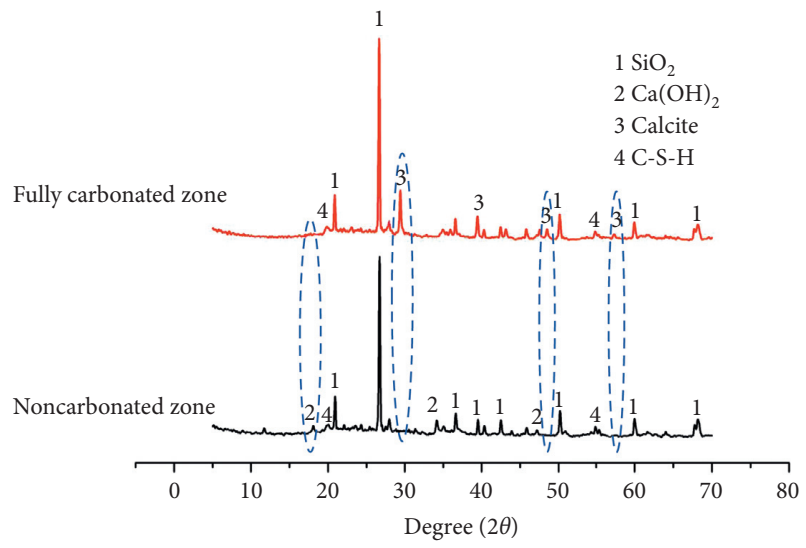

FIGURE 15: XRD results of different carbonated zones in the specimen.

delayed during long-term periods, as shown in Figures 6 and 10.

Mineralogical compositions and micromorphology measured in noncarbonated and fully carbonated zones are shown in Figure 17. Evidently, the plain-like $\mathrm{Ca}(\mathrm{OH})_{2}$ and amorphous $\mathrm{C}-\mathrm{S}-\mathrm{H}$ gel can be observed in lime-stabilized expansive soil (Figure 17(a) and $17(\mathrm{~b})$ ), while $\mathrm{CaCO}_{3}$ with typical cuneiform crystal structure can be observed in the specimen experiencing carbonation. Interparticle pores are clogged by the produced $\mathrm{CaCO}_{3}$, resulting in enhanced densification of the specimen as shown in Figure 17(c). Such microstructural changes may delay the evolution of carbonation depth and carbonation extent as shown in Figures 6 and 10. 


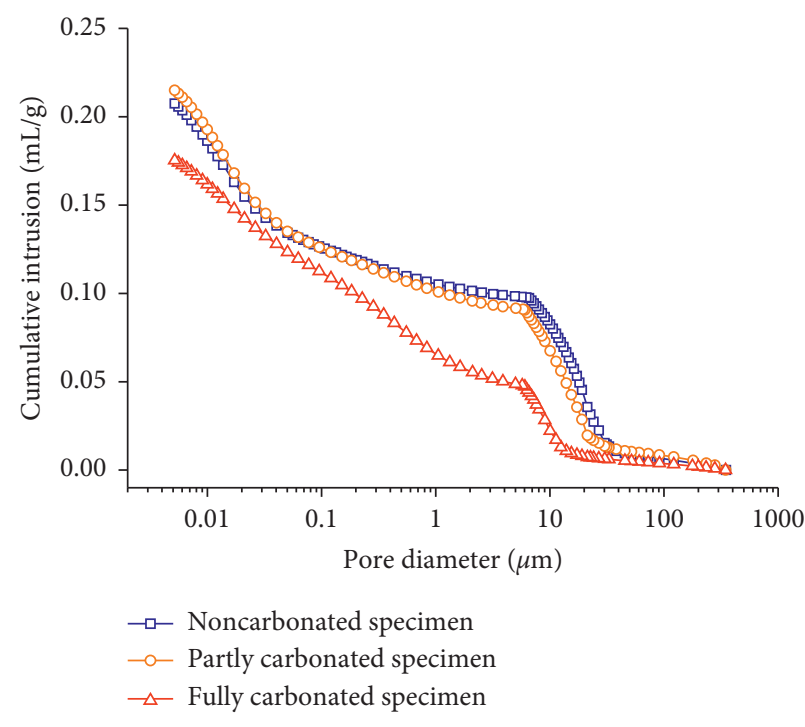

(a)

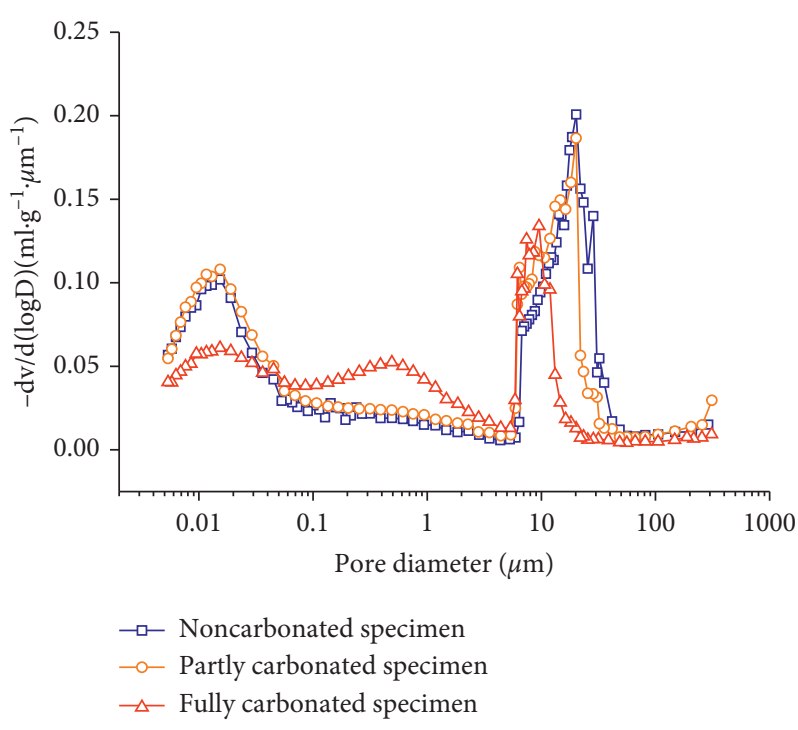

(b)

FIGURE 16: MIP results of different carbonated zones in the specimen. (a) Cumulative intrusion volume. (b) Differential intrusion volume.

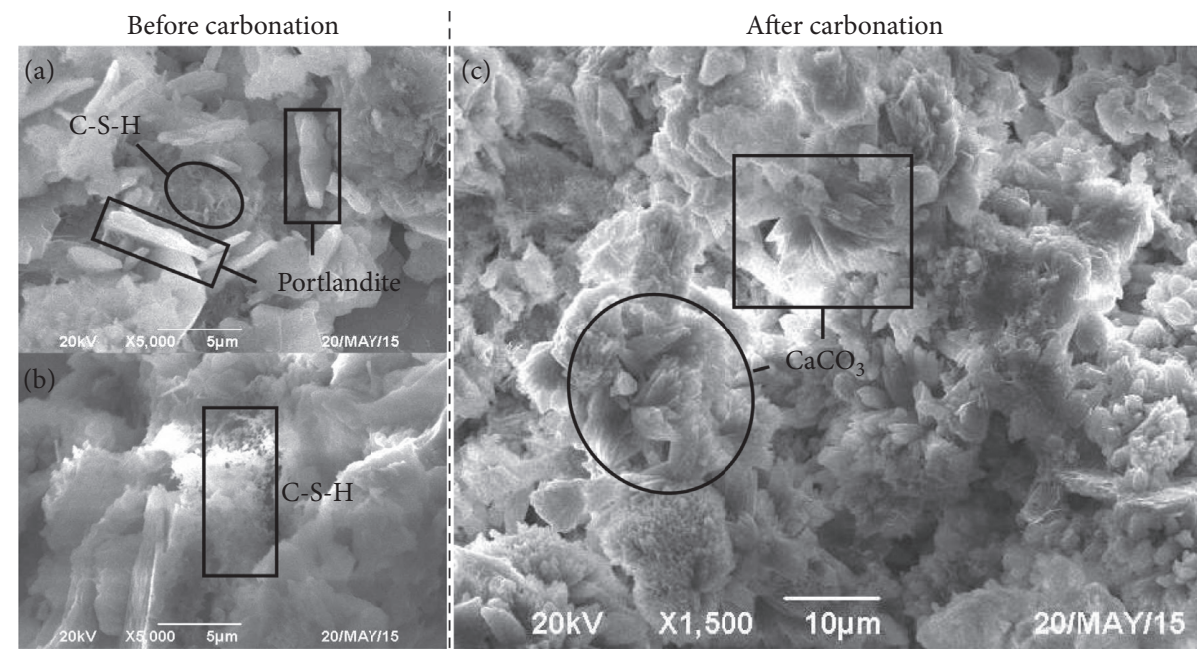

FIGURE 17: SEM results of different carbonated zones in the specimen. (a, b) Before carbonation. (c) After carbonation.

\section{Conclusions}

For investigating the carbonation behavior of lime-stabilized expansive soil, the accelerated carbonation test, $\mathrm{pH}$ value distribution measurement, free swell ratio, and microstructural analysis were conducted. The conclusions drawn from the study are as follows:

(1) Carbonation depth of lime-stabilized expansive soil increased significantly with time; however, the increasing rate became stable over a long period of time. Higher temperature and $\mathrm{CO}_{2}$ concentration along with lower relative humidity in the environment resulted in deep carbonation depths. Evolution of carbonation depth with time was predicted by an established empirical model, in which the influences of changes in temperature, relative humidity, and carbon dioxide concentration were considered.
(2) Carbonation extent in lime-stabilized expansive soil was reflected by the measured $\mathrm{pH}$ value distribution, through which the nonuniform distribution of carbonation extent was observed. The $\mathrm{pH}$ values were significantly lower than 9 (even approaching 6) at the top surface, indicating the fully carbonated zone of the specimen. With an increase in depth, the $\mathrm{pH}$ value also increased and became stable at a value of 11.4, indicating the noncarbonated zone in the specimen. Additionally, specimens experiencing longer carbonation time owned a higher carbonation extent at a given depth.

(3) The expansive potential of lime-stabilized soil was recovered after carbonation. A high free swell ratio of $30 \%$ was observed at the top zone of the specimen. With an increase in depth from the top of the specimen, the recovered expansive potential became 
limited. At a given depth, the expansive potential was enhanced with an increase in the carbonation time.

(4) The acquired linear relationships between the free swell ratio and $\mathrm{pH}$ value confirmed a strong dependency of expansive potential on the carbonation extent. The evolution of expansive behavior with carbonation time and depth was finally described based on the measured $\mathrm{pH}$ value distribution.

(5) Microstructural analysis confirmed that the conversion of portlandite into calcium carbonate controlled the carbonation behavior in lime-stabilized expansive soil. The total pore volume significantly reduced after carbonation. Although the amount of medium-sized pore, of around $0.5 \mu \mathrm{m}$, increased slightly after carbonation, the amount of small-sized and large-sized pores notably reduced during carbonation.

\section{Data Availability}

The data used to support the findings of this study are available from the corresponding author upon request.

\section{Conflicts of Interest}

The authors declare that they have no conflicts of interest.

\section{Acknowledgments}

The authors are grateful to the National Natural Science Foundation of China (project nos. 41807239, 41877262, and 41672306), the Special Project for Major Science and Technology in Anhui Province, China (project no. 18030801103), the Fundamental Research Funds for the Central Universities (project no. JZ2018HGBZ0136), and the "Qingmiao" talent project at the School of Resource and Environmental Engineering, Hefei University of Technology, for their financial support.

\section{References}

[1] Z.-G. Chen, C. S. Tang, C. Zhu et al., "Compression, swelling and rebound behavior of GMZ bentonite/additive mixture under coupled hydro-mechanical condition," Engineering Geology, vol. 221, pp. 50-60, 2017.

[2] T. Zhang, Y. F. Deng, Y. J. Cui et al., "Porewater salinity effect on flocculation and desiccation cracking behaviour of kaolin and bentonite considering working condition," Engineering Geology, vol. 251, pp. 11-23, 2019.

[3] Q. Cheng, C. S. Tang, H. Zeng et al., "Effects of microstructure on desiccation cracking of a compacted soil," Engineering Geology, vol. 265, p. 105418, 2020.

[4] C. S. Tang, B. Shi, C. Liu, W. B. Suo, and L. Gao, "Experimental characterization of shrinkage and desiccation cracking in thin clay layer," Applied Clay Science, vol. 52, no. 1-2, pp. 69-77, 2011.

[5] F. Wang, H. Wang, F. Jin, H. Al-Tabbaa, F. Jin, and A. AlTabbaa, "The performance of blended conventional and novel binders in the in-situ stabilisation/solidification of a contaminated site soil," Journal of Hazardous Materials, vol. 285, pp. 46-52, 2015.
[6] Y.-J. Du, N. J. Jiang, S. L. Shen et al., "Experimental investigation of influence of acid rain on leaching and hydraulic characteristics of cement-based solidified/stabilized lead contaminated clay," Journal of Hazardous Materials, vol. 225226, pp. 195-201, 2012.

[7] C.-S. Tang, C. Zhu, T. Leng et al., "Three-dimensional characterization of desiccation cracking behavior of compacted clayey soil using X-ray computed tomography," Engineering Geology, vol. 255, pp. 1-10, 2019.

[8] H. Xie, Y. S. Jiang, Y. Jiang, S. J. Feng, C. Zhang, and S. Feng, "An analytical model for volatile organic compound transport through a composite liner consisting of a geomembrane, a GCL, and a soil liner," Environmental Science and Pollution Research, vol. 22, no. 4, pp. 2824-2836, 2015.

[9] Y.-J. Du, M. L. Wei, K. R. Reddy et al., "Effect of carbonation on leachability, strength and microstructural characteristics of KMP binder stabilized $\mathrm{Zn}$ and $\mathrm{Pb}$ contaminated soils," Chemosphere, vol. 144, pp. 1033-1042, 2016.

[10] Y. Deng, X. Yue, S. Liu et al., "Hydraulic conductivity of cement-stabilized marine clay with metakaolin and its correlation with pore size distribution," Engineering Geology, vol. 193, pp. 146-152, 2015.

[11] A. Al-Taie, M. M. Disfani, R. Evans et al., "Swell-shrink cycles of lime stabilized expansive subgrade," Procedia Engineering, vol. 143, pp. 615-622, 2016.

[12] X. Dong, Z. W. Song, Y. F. Chen, Z. Song, and Y. F. Chen, "Electrical resistivity and strength properties of sodium hydroxide contaminated soil solidified with cement," Materials Testing, vol. 58, no. 1, pp. 82-87, 2016.

[13] S.-J. Feng, B. Y. Cao, A. Z. Li et al., "CFD modeling of hydrobiochemical behavior of MSW subjected to leachate recirculation," Environmental Science and Pollution Research, vol. 25, no. 6, pp. 5631-5642, 2018.

[14] A. Younsi, P. Turcry, A. Aït-Mokhtar et al., "Accelerated carbonation of concrete with high content of mineral additions: effect of interactions between hydration and drying," Cement and Concrete Research, vol. 43, pp. 25-33, 2013.

[15] Y.-s. Ji, M. Wu, B. Ding et al., "The experimental investigation of width of semi-carbonation zone in carbonated concrete," Construction and Building Materials, vol. 65, pp. 67-75, 2014.

[16] P. Turcry, L. Oksri-Nelfia, A. Younsi et al., "Analysis of an accelerated carbonation test with severe preconditioning," Cement and Concrete Research, vol. 57, pp. 70-78, 2014.

[17] H. Cui, W. C. Tang, W. Liu et al., "Experimental study on effects of $\mathrm{CO}_{2}$ concentrations on concrete carbonation and diffusion mechanisms," Construction and Building Materials, vol. 93, pp. 522-527, 2015.

[18] K. Zhang, J. Z. Xiao, and J. Xiao, "Prediction model of carbonation depth for recycled aggregate concrete," Cement and Concrete Composites, vol. 88, pp. 86-99, 2018.

[19] C.-f. Lu, W. Wang, Q. T. Li et al., "Effects of micro-environmental climate on the carbonation depth and the $\mathrm{pH}$ value in fly ash concrete," Journal of Cleaner Production, vol. 181, pp. 309-317, 2018.

[20] V.-L. Ta, S. Bonnet, K. T. Senga et al., "A new meta-model to calculate carbonation front depth within concrete structures," Construction and Building Materials, vol. 129, pp. 172-181, 2016.

[21] V. L. Ta, K. T. Senga, S. Bonnet, and A. Ventura, “Application of sensitivity analysis in the life cycle design for the durability of reinforced concrete structures in the case of XC4 exposure class," Cement and Concrete Composites, vol. 87, pp. 53-62, 2018. 
[22] J. J. Chang, W. Yeih, R. Huang et al., "Suitability of several current used concrete durability indices on evaluating the corrosion hazard for carbonated concrete," Materials Chemistry and Physics, vol. 84, no. 1, pp. 71-78, 2004.

[23] N. Hyvert, A. Sellier, F. Duprat et al., "Dependency of C-S-H carbonation rate on $\mathrm{CO}_{2}$ pressure to explain transition from accelerated tests to natural carbonation," Cement and Concrete Research, vol. 40, no. 11, pp. 1582-1589, 2010.

[24] A. Younsi, P. Turcry, E. Rozière et al., "Performance-based design and carbonation of concrete with high fly ash content," Cement and Concrete Composites, vol. 33, no. 10, pp. 9931000, 2011.

[25] B. Bary, A. Sellier, and A. Sellier, "Coupled moisture-carbon dioxide-calcium transfer model for carbonation of concrete," Cement and Concrete Research, vol. 34, no. 10, pp. 1859-1872, 2004.

[26] K. Sisomphon, L. Franke, and L. Franke, "Carbonation rates of concretes containing high volume of pozzolanic materials," Cement and Concrete Research, vol. 37, no. 12, pp. 1647-1653, 2007.

[27] M. Thiery, G. Villain, P. Dangla et al., "Investigation of the carbonation front shape on cementitious materials: effects of the chemical kinetics," Cement and Concrete Research, vol. 37, no. 7, pp. 1047-1058, 2007.

[28] H.-W. W. Song, S. J. Kwon, and S.-J. Kwon, "Permeability characteristics of carbonated concrete considering capillary pore structure," Cement and Concrete Research, vol. 37, no. 6, pp. 909-915, 2007.

[29] Q. Chen, Y. Ke, L. Zhang et al., "Application of accelerated carbonation with a combination of $\mathrm{Na} 2 \mathrm{CO} 3$ and $\mathrm{CO} 2$ in cement-based solidification/stabilization of heavy metalbearing sediment," Journal of Hazardous Materials, vol. 166, no. 1, pp. 421-427, 2009.

[30] K. Nakarai, T. Yoshida, and T. Yoshida, "Effect of carbonation on strength development of cement-treated Toyoura silica sand," Soils and Foundations, vol. 55, no. 4, pp. 857-865, 2015.

[31] L. S. Ho, K. Nakarai, Y. Ogawa et al., "Strength development of cement-treated soils: effects of water content, carbonation, and pozzolanic reaction under drying curing condition," Construction and Building Materials, vol. 134, pp. 703-712, 2017.

[32] M. S. B. Shafique, J. C. Walton, N. Walton et al., "Influence of carbonation on leaching of cementitious wasteforms," Journal of Environmental Engineering, vol. 124, no. 5, pp. 463-467, 1998.

[33] R. E. H. Sweeney, C. D. Hills, and N. R. Buenfeld, Acid Neutralisation Capacity of Carbonated Solidified Waste, Imperial College of Science Technology and Medicine, London, UK, 1999.

[34] L. C. Lange, C. D. Hills, A. B. Poole, C. D. Hills, and A. B. Poole, "The effect of accelerated carbonation on the properties of cement-solidified waste forms," Waste Management, vol. 16, no. 8, pp. 757-763, 1996.

[35] M. F. Bertos, S. J. R. Simon, C. D. Hills, and P. J. Carey, “A review of accelerated carbonation technology in the treatment of cement-based materials and sequestration of $\mathrm{CO}_{2}$," Journal of Hazardous Materials, vol. 112, no. 3, pp. 193-205, 2004.

[36] Y. Cheng, S. Wang, J. Li et al., "Engineering and mineralogical properties of stabilized expansive soil compositing lime and natural pozzolans," Construction and Building Materials, vol. 187, pp. 1031-1038, 2018.

[37] T. Fukushima, Y. Yoshizaki, F. Tomosawa, and K. Takahashi, "Relationship between neutralization depth and concentration distribution of $\mathrm{CaCO}_{3}-\mathrm{Ca}(\mathrm{OH})_{2}$ in carbonated concrete," in Advances in Concrete Technology, V. M. Malhotra, Ed., pp. 347-363, ACI SP-179, Tokushima, Japan, 1998.

[38] C.-F. Chang, J. W. Chen, and J.-W. Chen, "The experimental investigation of concrete carbonation depth," Cement and Concrete Research, vol. 36, no. 9, pp. 1760-1767, 2006.

[39] M. Moreno, W. Morris, M. G. Alvarez et al., "Corrosion of reinforcing steel in simulated concrete pore solutions," Corrosion Science, vol. 46, no. 11, pp. 2681-2699, 2004.

[40] V. Shah, K. Scrivener, B. Bhattacharjee et al., "Changes in microstructure characteristics of cement paste on carbonation," Cement and Concrete Research, vol. 109, pp. 184-197, 2018.

[41] W. L. Jin and Y. X. Zhao, Durability of Concrete Structures, Science Press, Beijing, China, 2014.

[42] A. Morandeau, M. Thiéry, P. Dangla, M. Thiéry, and P. Dangla, "Investigation of the carbonation mechanism of $\mathrm{CH}$ and $\mathrm{C}-\mathrm{S}-\mathrm{H}$ in terms of kinetics, microstructure changes and moisture properties," Cement and Concrete Research, vol. 56, pp. 153-170, 2014.

[43] M. Castellote, C. Andrade, X. Turrillas et al., "Accelerated carbonation of cement pastes in situ monitored by neutron diffraction," Cement and Concrete Research, vol. 38, no. 12, pp. 1365-1373, 2008. 